\title{
Complete necrosis of hepatocellular carcinoma after preoperative portal vein embolization: a case report
}

\author{
H EL Bacha ${ }^{1,2^{*}}$, M Salihoun $^{1,2}$, N Kabbaj ${ }^{1,2}$ and A Benkabbou ${ }^{1,3}$
}

\begin{abstract}
Background: Hepatocellular carcinoma has a poor prognosis; few patients can undergo surgical curative treatment according to Barcelona Clinic Liver Cancer guidelines. Progress in surgical techniques has led to operations for more patients outside these guidelines. Our case shows a patient with intermediate stage hepatocellular carcinoma presenting a good outcome after curative treatment.

Case presentation: We report the case of an 80-year-old Moroccan man, who was positive for hepatitis c virus, presenting an intermediate stage hepatocellular carcinoma (three lesions between 20 and $60 \mathrm{~mm}$ ). He presented a complete tumor necrosis after portal vein embolization and achieved 24-month disease-free survival after surgery.

Conclusions: Perioperative care in liver surgery and multidisciplinary discussion can help to extend indications for liver resection for hepatocellular carcinoma outside European Association for the Study of the Liver/American Association for the Study of Liver Diseases recommendations and offer a curative approach to selected patients with intermediate and advanced stage hepatocellular carcinoma.
\end{abstract}

Keywords: Hepatocellular carcinoma, Portal vein embolization, Liver resection, Complete tumor necrosis

\section{Background}

Less than one out of three patients diagnosed with hepatocellular carcinoma (HCC) may undergo a curative treatment: liver resection, liver transplantation, or percutaneous ablation [1]. Refinement of surgical techniques and perioperative care helped to extend indications for liver resection for HCC outside European Association for the Study of the Liver (EASL)/American Association for the Study of Liver Diseases (AASLD) recommendations with encouraging short-term and long-term outcomes [2]. When a liver resection of more than three segments is considered, preoperative portal vein embolization (PVE) is of critical importance because it induce a significant growth of the remnant liver, and prevent a potentially lethal postoperative liver failure [3]. Because of a main arterial supply, HCC may respond to

\footnotetext{
* Correspondence: elbachahicham@hotmail.fr

${ }^{1}$ Faculté de médecine et de pharmacie de Rabat, Mohammed V University, Rabat, Morocco

${ }^{2}$ Explorations Fonctionnelles Digestives, Ibn Sina Hospital, Rabat, Morocco Full list of author information is available at the end of the article
}

transarterial embolization or transarterial chemoembolization (TACE) but not PVE. We report a case of a complete histological necrosis of a HCC after preoperative right PVE.

\section{Case presentation}

An 80-year-old Moroccan man presented with a 4-month history of nonspecific abdominal pain and asthenia, he had no comorbidity except late onset asthma. His performance status was good (PS 0 to 1 ) and a physical examination unremarkable. Abdominal imaging (ultrasound and contrast-enhanced computed tomography) showed three liver lesions of $20 \mathrm{~mm}$ (liver segment 7), $27 \mathrm{~mm}$ (liver segment 5), and $60 \mathrm{~mm}$ (liver segment 6). None of the three lesions fulfilled imaging diagnosis criteria for HCC (Fig. 1; poor arterial enhancement). His spleen size was normal and there was no sign of portal hypertension. Laboratory tests found a slight cytolysis of 1.4-fold normal value. His serum dosage of bilirubin and albumin, and prothrombin time were normal. His serum 

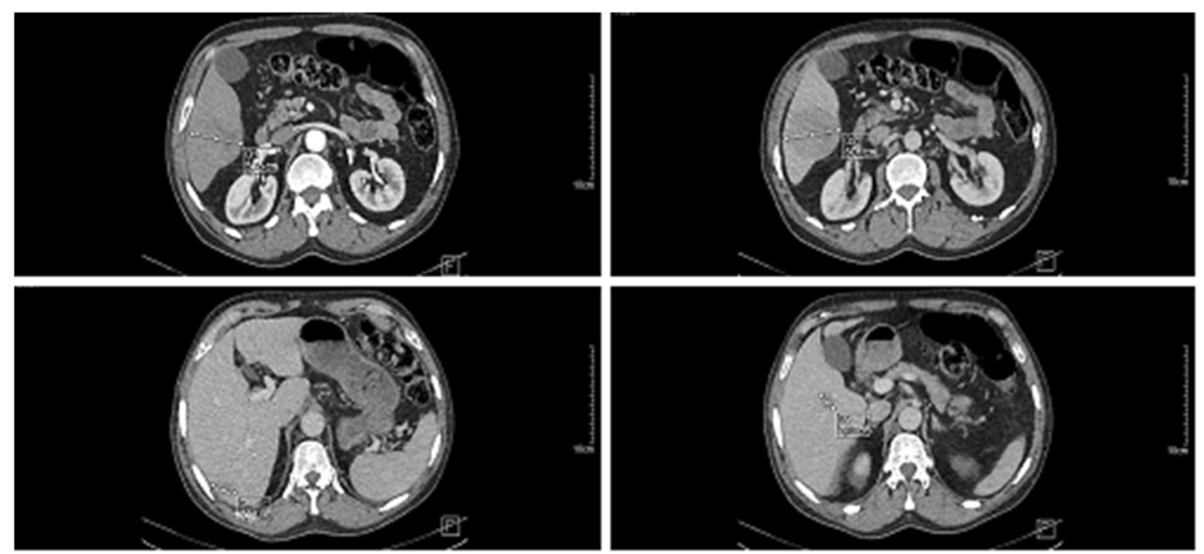

Fig. 1 Enhanced computed tomography images showing three liver lesions of 20 mm (liver segment 7), 27 mm (liver segment 5), and 60 mm (liver segment 6)

alpha-fetoprotein (AFP) value was $341.40 \mathrm{ng} / \mathrm{ml}$ (normal value $<5 \mathrm{ng} / \mathrm{ml}$ ). Hepatitis $\mathrm{C}$ virus ( $\mathrm{HCV}$ ) serology was positive for a genotype $1 \mathrm{~b}$ virus with a viral load of $4.36 \mathrm{log}$. Hepatitis B virus (HBV) serology was negative. Pathology analysis of percutaneous liver and tumor (liver segment 6) biopsy showed respectively a chronic active hepatitis A3F2 according to METAVIR score and a well-differentiated HCC, staging our patient as an intermediate stage $\mathrm{B}$ according to the Barcelona Clinic Liver Cancer (BCLC) algorithm. After a multidisciplinary meeting, we decided his treatment should be a right hepatectomy. Calculation of the future remnant liver volume (FRL) by software technique found FRL (left liver and segment 1) of $340 \mathrm{ml}$. A percutaneous portal embolization using ipsilateral technique (embolization of right portal vein collaterals through right liver puncture) was performed with subsequent FRL hypertrophy: $640 \mathrm{ml}$ (+53\%) after 4 weeks. An open right hepatectomy was performed. Specimen pathology analysis found three welllimited nodules with necrotic-hemorrhagic remodeling with a total tumor necrosis and lack of perennial tumor cell in microscopy. His postoperative courses were uneventful. $\mathrm{He}$ is alive and free from disease after a follow-up of 24 months.

\section{Discussion}

The effect of PVE on HCC remains controversial and is not well established. Some authors have suggested an anti-tumor effect of PVE on HCC related to partial tumor necrosis after portal thrombosis [4] or total tumor necrosis after PVE [5]. Others suggested a pro-tumor effect of PVE on primary tumors of the liver $[6,7]$ that may be explained by: (1) the compensatory augmentation of the arterial flow to the tumor after PVE [8], (2) expression of cytoprotective genes involved in remodeling and cell repair as a response to the stress, and (3) induction and modulation of cytokine secretion and growth factors such as tumor necrosis factor (TNF) and hepatocyte growth factor (HGF) [7].

Our report showed a complete histological necrosis of a well-differentiated $\mathrm{HCC}$ after preoperative right PVE. This result was unexpected because $\mathrm{HCC}$ have a predominant arterial vascularization [9]. Hypothesis 1: some HCC may have predominant portal vascularization. In our patient, this may have been the case as initial imaging showed poor arterial enhancement. Hypothesis 2: a spontaneous regression may occur. Spontaneous regression is defined by a complete or partial clearance of malignant cells in the absence of all treatment or in the presence of therapy that is considered inadequate to exert a significant influence on the neoplastic disease. From a physiopathology point of view, this phenomenon may be caused by hypoxia due to rapid tumor growth, tumor infarction following hemorrhagic shock, circulatory failure by arterial thrombosis or venous thrombosis, or reactivation and recognition of tumor cells by the immune system. Spontaneous regression may occur in approximately $1 / 100,000$ patients with malignant tumor including HCC. Only 12 pathologically proven cases of $\mathrm{HCC}$ regression (including our case) have been reported in the literature [10]. Hypothesis 3: an arterial trauma may cause ischemia. In fact, an asymptomatic proximal intrahepatic arterial trauma may be caused during fine liver biopsy and/or percutaneous PVE procedure. This last hypothesis is validated by the facts that in our patient, PVE was performed with multiple right liver (ipsilateral) punctures and that complete necrosis was recorded in all of the three lesions. In our opinion, combined disruption of a predominant portal flow by PVE (hypothesis 1) and arterial flow by a puncture trauma may explain the result in our patient.

Complete necrosis should have been suspected while performing a second preoperative liver imaging to assess future liver remnant hypertrophy but it would not have 
changed our surgical strategy. In fact, relapse of spontaneously necrotized HCC has been reported [11] and viable persistence of tumoral cells has also been often observed despite a diagnosis of advanced tumor necrosis in imaging examinations [12].

\section{Conclusions}

Refinement of perioperative care in liver surgery, including preoperative portal embolization and multidisciplinary discussion, has helped to extend indications for liver resection for HCC outside EASL/AASLD recommendations and offers a curative approach to selected patients with intermediate (our patient) and advanced stage HCC.

\begin{abstract}
Abbreviations
AASLD: American Association for the Study of Liver Diseases; AFP: Alphafetoprotein; BCLC: Barcelona Clinic Liver Cancer; EASL: European Association for the Study of the Liver; FRL: Future remnant liver volume; HBV: Hepatitis B virus; HCC: Hepatocellular carcinoma; HCV: Hepatitis C virus; HGF: Hepatocyte growth factor; PS: Performance status; PVE: Portal vein embolization;

TACE: Transarterial chemoembolization; TNF: Tumor necrosis factor
\end{abstract}

\section{Acknowledgements}

There are no other contributors but the authors.

\section{Funding}

No funds were received in support of this study.

\section{Availability of data and materials}

Data and supporting materials are available freely to any scientist wishing to use them.

\section{Authors' contributions}

EBH was the patient's physician, in charge of the diagnosis and the follow up, he wrote the manuscript. SM was the professor in charge of the medical care and the following of the patient and did the first correction of the paper. $\mathrm{KN}$ is the chief of the medical department and took therapeutic decisions for the patient in the multidisciplinary meeting. BA is the surgeon of the patient who performed the portal vein embolization and the surgery; he corrected and rewrote the manuscript. All authors read and approved the final manuscript.

\section{Competing interests}

The authors declare that they have no competing interests.

\section{Consent for publication}

Written informed consent was obtained from the patient for publication of this case report and any accompanying images. A copy of the written consent is available for review by the Editor-in-Chief of this journal.

\section{Ethics approval and consent to participate}

Not applicable.

\section{Author details}

${ }^{1}$ Faculté de médecine et de pharmacie de Rabat, Mohammed V University, Rabat, Morocco. ${ }^{2}$ Explorations Fonctionnelles Digestives, Ibn Sina Hospital, Rabat, Morocco. ${ }^{3}$ Surgical Department A, Ibn Sina Hospital, Rabat, Morocco.

Received: 25 June 2016 Accepted: 24 November 2016

Published online: 04 January 2017

\section{References}

1. Bruix J, Llovet JM. Major achievements in hepatocellular carcinoma. Lancet. 2009;373:614-6.

2. Torzilli G, Belghiti J, Kokudo N, Takayama T, Capussotti L, Nuzzo G, Vauthey JN, Choti MA, De Santibanes E, Donadon M, Morenghi E, Makuuchi M. A snapshot of the effective indications and results of surgery for hepatocellular carcinoma in tertiary referral centers: is it adherent to the EASL/AASLD recommendations?: an observational study of the HCC Eastwest study group. Ann Surg. 2013;257(5):929-37.

3. Abulkhir A, Limongelli $P$, Healey AJ, et al. Preoperative portal vein embolization for major liver resection: a meta-analysis. Ann Surg. 2008;247:49-57.

4. Tomino T, Yamashita Y, lguchi T, et al. Spontaneous Massive Necrosis of Hepatocellular Carcinoma with Narrowing and Occlusion of the Arteries and Portal Veins. Case Rep Gastroenterol. 2014;8(1):148-55. doi:10.1159/000362440.

5. Ogata S, Belghiti J, Farges O, Varma D, Sibert A, Vilgrain V. Sequential arterial and portal vein embolizations before right hepatectomy in patients with cirrhosis and hepatocellular carcinoma. Br J Surg. 2006;93:1091-8.

6. Hayashi S, Baba Y, Ueno K, Nakajo M, Kubo F, Ueno S, et al. Acceleration of primary liver tumor growth rate in embolized hepatic lobe after portal vein embolization. Acta Radiol. 2007:48:721-7. Epub 2007/08/31.

7. De Graaf W, van den Esschert JW, van Lienden KP, van Gulik TM. Induction of tumor growth after preoperative portal vein embolization: is it a real problem? Ann Surg Oncol. 2009;16:423-30. Epub 2008/12/04.

8. Nagino M, Nimura Y, Kamiiya J, et al. Immediate increase in arterial blood flow in embolized hepatic segments after portal vein embolization: CT demonstration. AJR Am J Roentgenol. 1998;171:1037-9.

9. Cazejust J, Bessoud B, Colignon N, Garcia-Alba C, Planché O, Menu Y. Hepatocellular carcinoma vascularization: from the most common to the lesser known arteries. Diagn Interv Imaging. 2014;95:27-36.

10. Saito $R$, Amano $H$, Abe $T$, et al. Complete spontaneous necrosis of hepatocellular carcinoma confirmed on resection: A case report. Int J Surg Case Rep. 2016;22:70-4.

11. Lee HS, Lee JS, Woo GW, et al. Recurrent hepatocellular carcinoma after spontaneous regression. J Gastroenterol. 2000;35:552-6.

12. Sasaki T, Fukumori D, Yamamoto K, Yamamoto F, Igimi H, Yamashita Y. Management Considerations for Purported Spontaneous Regression of Hepatocellular Carcinoma: A Case Report. Case Rep Gastroenterol. 2013;7(1): 147-52. doi:10.1159/000350501.
Submit your next manuscript to BioMed Central and we will help you at every step:

- We accept pre-submission inquiries

- Our selector tool helps you to find the most relevant journal

- We provide round the clock customer support

- Convenient online submission

- Thorough peer review

- Inclusion in PubMed and all major indexing services

- Maximum visibility for your research

Submit your manuscript at www.biomedcentral.com/submit
Biomed Central 